\title{
Retrospective Analysis of American Woodcock Population and Harvest Trends in Canada
}

CHRISTIAN ROY, ${ }^{1}$ Canadian Wildlife Service - National Capital Region, Environment and Climate Change Canada, Gatineau, Quebec, Canada.

MICHEL GENDRON, Canadian Wildlife Service - National Wildlife Research Centre, Environment and Climate Change Canada, Ottawa, Ontario, Canada.

SHAWN W. MEYER, Canadian Wildlife Service - Ontario Region, Environment and Climate Change Canada, Ottawa, Ontario, Canada.

J. BRUCE POLLARD, Canadian Wildlife Service - Atlantic Region, Environment and Climate Change Canada, New Brunswick, Canada.

JEAN RODRIGUE, Canadian Wildlife Service - Quebec Region, Environment and Climate Change Canada, Québec City, Quebec, Canada.

J. RYAN ZIMMERLING, Canadian Wildlife Service - National Capital Region, Environment and Climate Change Canada, Gatineau, Quebec, Canada.

ABSTRACT We used data from the Canadian component of the annual American Woodcock Singing-ground Survey (SGS) and data from the Canadian National Harvest Survey between 1975 and 2015 to assess temporal fluctuations in the population index, the number of American woodcock (Scolopax minor; hereafter, woodcock) harvested in Canada, and the proportion of successful hunters in Canada. We performed analyses via generalized additive mixed models that allowed us to identify periods when there were significant changes in temporal trends, and years during which there were significant changes in the direction of the temporal trajectory. We included climatic conditions before, during, and after the nesting and brood-rearing seasons (i.e., prior to the hunting season) as explanatory variables in our model. We did not find any effect of climatic variables on the SGS index. The SGS population index showed a slow overall negative decline in Canada, but there were only 2 significant periods of decline (1978-1984 and 1992-1994). Woodcock harvest and the proportion of successful woodcock hunters increased with the size of the SGS population index in the spring. The total harvest and the proportion of successful hunters remained fairly stable during the study period, but both indices showed a period of significant decline that started ca. 2006, and that was followed by a period of significant increase that started ca. 2009.

Proceedings of the American Woodcock Symposium 11: 228-239

KEY WORDS: American woodcock, generalized additive mixed model, population change, population trend, harvest, Singing Ground Survey

The American woodcock (Scolopax minor; hereafter woodcock) is a migratory game bird that inhabits early successional deciduous forests of eastern Canada and the United
States. The woodcock is managed under the Convention for the Protection of Migratory Birds in Canada and the United States, and woodcock populations are monitored

1 email: christian.roy3@canada.ca 
using the Singing-ground Survey (SGS), coordinated by the U. S. Fish and Wildlife Service (USFWS) and the Canadian Wildlife Service (CWS). The continental population of woodcock has shown long-term declines since the inception of the SGS in 1968 (Seamans and Rau, this volume). Although the most recent estimate (Seamans and Rau, this volume) indicates that population trends have stabilized in the Central Management Regions in the last 10 years, populations in the Eastern Management Region have declined during the same period, and concern remains over longterm woodcock population trajectories (Seamans and Rau, this volume). The current prevailing theory to explain the species' decline is loss of early successional forest in the southern part of its breeding range (McAuley et al. 1996, Kelley et al. 2008). These concerns have led to the development of a harvest strategy to regulate harvest in the United States, and the development of a conservation plan (Kelley et al. 2008).

Woodcock harvest is also monitored through harvest surveys. In Canada, this is done through the National Harvest Survey, which consists of the Species Composition Survey and the Harvest Questionnaire Survey. The Harvest Questionnaire Survey is mailed nation-wide to approximately 45,000 Migratory Game Bird Hunting Permit holders with questions mainly focused on waterfowl hunting. However, some information is collected for non-waterfowl game birds (e.g., woodcock). From these data, management agencies such as CWS can estimate the number of woodcock harvested, the number of successful woodcock hunters, and the average number of woodcock harvested in a hunting area (e.g., province or zone). Although these variables are used to inform harvest management of woodcock, they have never been used to identify potential population drivers, or to analyze potential long-term trends that would inform these management actions.

Effective management of a harvested population relies on the development of an effective monitoring program. This includes a mechanistic population model that explains why and how populations fluctuate, and a harvest-monitoring program that helps link harvest with population trends (Sutherland 2001, Ferrand et al. 2010, Evans 2012). Accordingly, 1 of the priorities that has been established in the woodcock recovery plan is development of a population model to assess the effect of harvest and habitat management on the population (Kelley et al. 2008). There have been few potential population drivers identified in the woodcock literature, but some studies have established links between weather conditions in the spring and woodcock productivity and survival. It has been demonstrated that spring climatic conditions can influence earthworm abundance and other foods consumed by woodcock (Vander Haegen et al. 1993) and the nesting and reproductive success of woodcock (Rabe et al. 1983), and that the amount of precipitation during spring and summer can affect woodcock adult and juvenile survival (Sepik et al. 1983, Daly et al. 2015).

Our first objective was to determine how spring climatic conditions affect the SGS population index and woodcock harvest in Canada. The second objective was to identify periods of significant long-term change in (1) the SGS population index, (2) the number of woodcock harvested in Canada, and (3) the proportion of successful hunters in Canada. We selected these 3 datasets as each contributes a component to overall understanding of trends in woodcock populations. The SGS population index provides valuable information on breeding population trends, while the National Harvest Survey tracks the fall woodcock population by utilizing the total harvest in the fall to inform managers of population trends and annual productivity. Total harvest data, however, can be biased due to unequal success rates for individual hunters. Harvest per unit of effort is usually positively skewed by more efficient hunters with high success rates, and these most-successful hunters are more likely to continue hunting regularly even in years of lower population numbers (Guthrey et al. 2004, Willebrand et al. 2011). The proportion of successful hunters (i.e., hunters that harvest $\geq 1$ woodcock), therefore, can be utilized to detect any changes in composition of hunters that would influence the trend in the harvest.

\section{Study Area}

Our study focused on the 5 Canadian provinces where woodcock regularly breed: Ontario, Quebec, New Brunswick, Prince Edward Island, and Nova Scotia. The study area is comprised of the Boreal Shield, Mixed Wood Plains, and Atlantic Maritime Ecoregions. Most of the land is covered by forest, with patches of row crop agriculture and urban areas concentrated in the southern portions of each province. Likewise, most private ownership of woodlands in our study area was located in the south, whereas more northern forests were generally under Crown tenure. The SGS spans the entirety of New Brunswick, Prince Edward Island, and Nova Scotia, but is limited south of the Boreal Softwood Shield Bird Conservation Region in Ontario and Quebec (Sauer et al. 2008). Hunting effort and harvest is concentrated in the southern hunting zones where the human population is concentrated (Gendron and Smith 2017).

\section{Methods}

\section{DATA SOURCES}

SGS population index Every year, a population index is derived from the SGS for the 2 broad management regions (Eastern and Central) and every province/state that participates in the survey. This index is based on the number of singing males that are counted via a roadside survey 
during the spring using a standardized protocol. Population trends are subsequently estimated using a hierarchical model (Sauer et al. 2008, Seamans and Rau, this volume). We obtained population indices between 1975 and 2015 from the 2016 American Woodcock population status report (Seamans and Rau 2016).

Canadian harvest and hunter success data We used the Canadian National Harvest Survey to obtain data on the number of harvested woodcock reported by hunters, the number of active non-waterfowl hunters, the number of days spent hunting by non-waterfowl hunters, and the number of successful woodcock hunters for each of the 5 provinces (Gendron and Smith 2017; Appendix 1). These variables were derived from Harvest Questionnaire Survey data. The complete methodology of the survey is available on Environment and Climate Change Canada's website (Environment and Climate Change Canada 2017). We used non-waterfowl hunters in our analysis, which included Mourning dove (Zenaida macroura), Wilson's snipe (Gallinago delicata), rails (Rallus limicola and Porzana carolina), and American coot (Fulica americana) hunters in addition to woodcock hunters, as the Harvest Questionnaire Survey is not directed only to woodcock hunters. We assumed that the proportion of woodcock hunters among non-waterfowl hunters has remained stable throughout the survey period. Woodcock wings are also collected during the Species Composition Survey, which can subsequently be used to estimate productivity. However, the dataset does not include wings collected before 1991 and does not include samples from Prince Edward Island, so we did not include these data in our analysis.

\section{ENVIRONMENTAL VARIABLES}

Snow cover Late spring weather conditions can negatively affect survival of woodcock and recruitment into the population (Dwyer et al. 1982, Longcore et al. 1996). Using snow cover as a proxy for spring phenology, we acquired the Snow Cover Extent from the National Oceanic and Atmospheric Administration (NOAA) National Center for Environmental Information website (NOAA 2018). The dataset consists of weekly gridded data $\left(1.0^{\circ} \mathrm{x}\right.$ $1.0^{\circ}$ ) documenting the occurrence of snow on the ground for the northern hemisphere (Robinson et al. 2012). For each year, in each province, we retrieved the average week during which the snow cover permanently disappeared from the ground. For Ontario and Quebec, we restricted the extraction of the snow cover values south of $51.75^{\circ} \mathrm{N}$ to avoid including areas that were not part of woodcock breeding range (McAuley et al. 2013).

Total precipitation The amount and timing of precipitation has been shown to limit the survival of woodcock juveniles during the brooding season and the survival of juveniles and adults during the summer (Rabe et al. 1983,
Sepik et al. 1983, Daly et al. 2015). We used the NOAA PRECipitation REConstruction over Land (PREC/L) dataset to measure the amount of precipitation that occurred during each year between 1 April and 31 July within each province. The dataset consists of monthly gridded $\left(1.0^{\circ} \mathrm{x}\right.$ $1.0^{\circ}$ ) interpolated precipitation predictions (Chen et al. 2002). We calculated the total amount of precipitation, in each province, before the nesting season (April), during the nesting/brooding season (May and June), and during the fledgling season (July). Similar to the snow cover index, we restricted the extraction of the data south of $51.75^{\circ} \mathrm{N}$ in Ontario and Quebec. We derived an index of wetness within each province by centering the data extracted on the log scale.

\section{DATA ANALYSIS}

General additive mixed-model framework We used generalized additive mixed models (GAMM) in a Bayesian framework for our analysis. GAMM can accommodate nonlinear relationships, which can be advantageous if the user wishes to delineate the shape of a trajectory over time. In all analysis we included explanatory variables and added 2 time components to separate potential temporal effects that are not explained by the explanatory variables:

$$
\mu_{i, t}=\mathrm{X} \beta+\mathrm{S}(t)+\varepsilon_{i, t}
$$

eq. 1

where $\mu_{i, t}$ is the mean on the link scale, $\mathrm{X}$ is a matrix of explanatory variables, $\beta$ is vector of linear coefficients (i.e., fixed effects) to be estimated, $\mathrm{S}(\mathrm{t})$ is shared cubic splines smoothing component for all 5 provinces, and $\varepsilon_{i, t}$ is a random year effect at the provincial level. The smoothing component represents a global temporal trend, unexplained by the explanatory variables, that was shared across all 5 provinces. The random year effect represents the individual deviations from the global trend at the provincial scale. If, for some reason, a province did not share the temporal global trend present in the other provinces, the yearly random effect of this province would show a significant temporal trend (Knape 2016). To avoid spurious results, we checked for correlations among predictors for each model. All pairwise correlations were found to be well below the acceptable threshold (i.e., >o.6).

For each model, we estimated the first and second derivative of the cubic splines smoothing component from the posterior distribution to assess evidence for significant change in the temporal trend. Significant changes in either the first or second derivative indicated significant temporal changes that were unaccounted for by the explanatory variables included in the model. In both cases, we deemed a change significant if the $95 \%$ Bayesian credible interval of the estimate did not overlap zero. Years when the first derivative was significant indicated that the trend increased, or decreased, significantly from the pre- 
vious year (Fewster et al. 2009, Knape 2016). Years when the second derivative was significantly positive indicated that the rate of change was turning upward (i.e., faster increase or slower decrease), whereas years when the second derivative was significantly negative indicated years of downturns (i.e., slower increase or faster decline). Years when the second derivative was significant are considered change points, and can help suggest external causes for the changes observed in a time series (Fewster et al. 2009, Knape 2016).

SGS population index in the provinces We analyzed the annual variation in SGS population index assuming a lognormal distribution. We included the effect of province, year, snow cover, and precipitation before the nesting season as fixed effect in the model. We expected that a late snow cover and a wet spring would have a negative impact on the SGS index because those conditions would make the breeding season difficult for males and negatively affect their inclination to display and their survival (Duke 1966). We also included the effect of snow cover during the previous year as a fixed effect in the model. We partitioned precipitation into 3 temporally explicit terms: 1 ) before the nesting season, 2) during the nesting/brooding season, 3) and during the fledgling season. We expected late snow cover to have a negative effect on nesting female success, wet conditions before and during the nesting and brood rearing seasons to negatively affect female productivity and juvenile survival, and dry conditions during the fledgling season to negatively affect both adult and juvenile survival. All of those factors should lead to a reduction in the fall woodcock population, and we expected the negative effects should be significant enough to persist during the winter and to be reflected in the SGS index the subsequent year.

Total harvest in the provinces We analyzed the harvest data using a Poisson distribution. We included year, province, SGS population index, snow cover, and precipitation as fixed effects in the model. We partitioned precipitation into the same temporally explicit terms as described above (i.e., before the nesting season, during the nesting/ brooding season, and during the fledgling season). We expected that those variables would have an effect similar to the effects we hypothesized on the SGS population index and that the a reduction in the fall woodcock population would negatively affect harvest and hunter success (Schulz et al. 2010), given that juveniles are likely more vulnerable to hunting than adults (Reynolds 1987, Zimmerman et al. 2010). Values for total harvest for a given province were sensitive in part to the number of estimated active non-waterfowl hunters in the National Harvest Survey dataset during each year. Given that we were interested in how harvest changed over time independently of effort, we included the log of the numbers of active non-waterfowl hunters as an offset in the model. Thus, the results
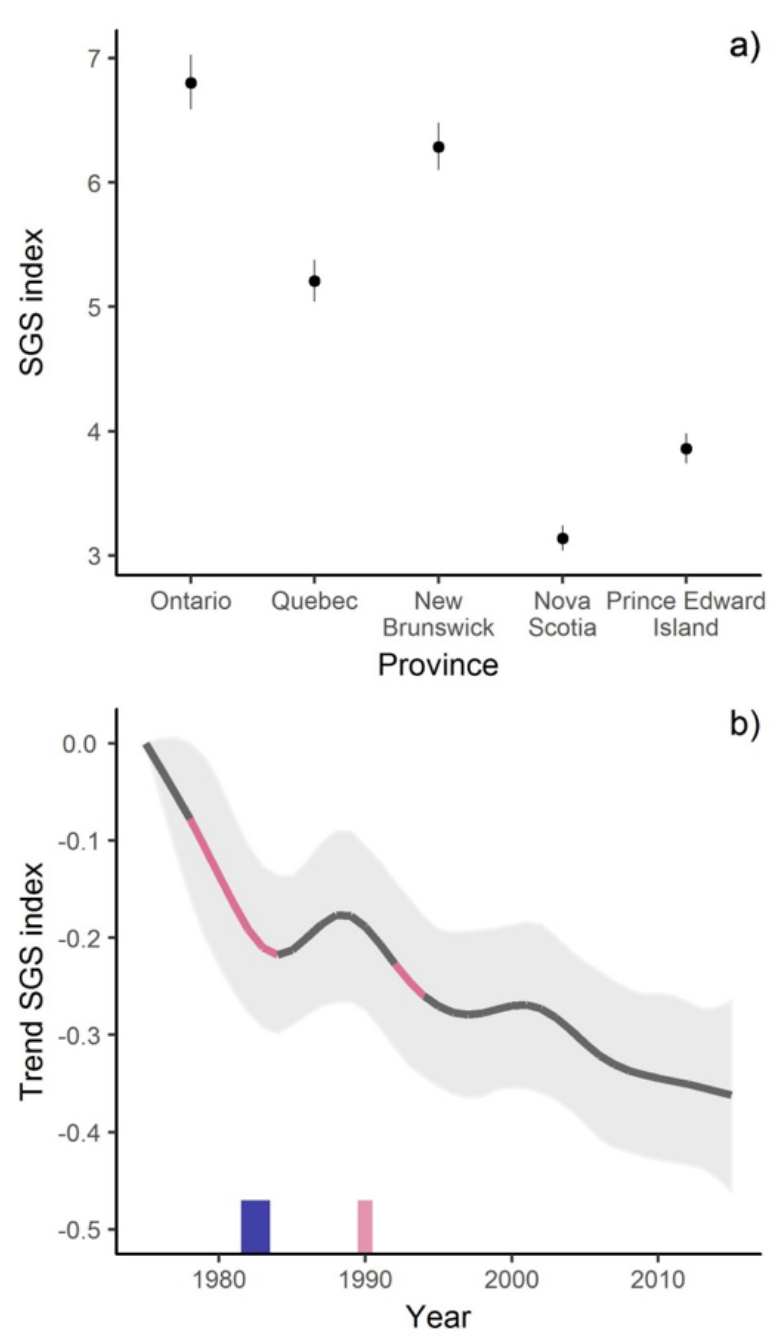

Figure 1. a) Estimated size of the American Woodcock Singing-Ground Survey (SGS) population index as a function of province at the beginning of the survey period (1975). Dots represent the mean and bars represent 95\% Bayesian credible intervals. b) shared temporal trend for the SGS across all 5 provinces during $1975-2015$.The solid line is the estimated long-term component of the trend, whereas the shaded area represents 95\% Bayesian credible intervals. The trend line is colored for periods where there is a significant decrease (pink) in the trend. Periods where the curvature is significantly positive (e.g., upturn; blue) or negative (e.g., downturn, pink) are identified by bars along the $\mathrm{x}$-axis.

and predictions that are derived from the model reflect the annual variation in harvest if the number of hunters would be held constant during the period at hand.

Proportion of successful hunters in the provinces We used a logistic distribution to analyze the annual variation in the proportion of successful hunters in each province. 


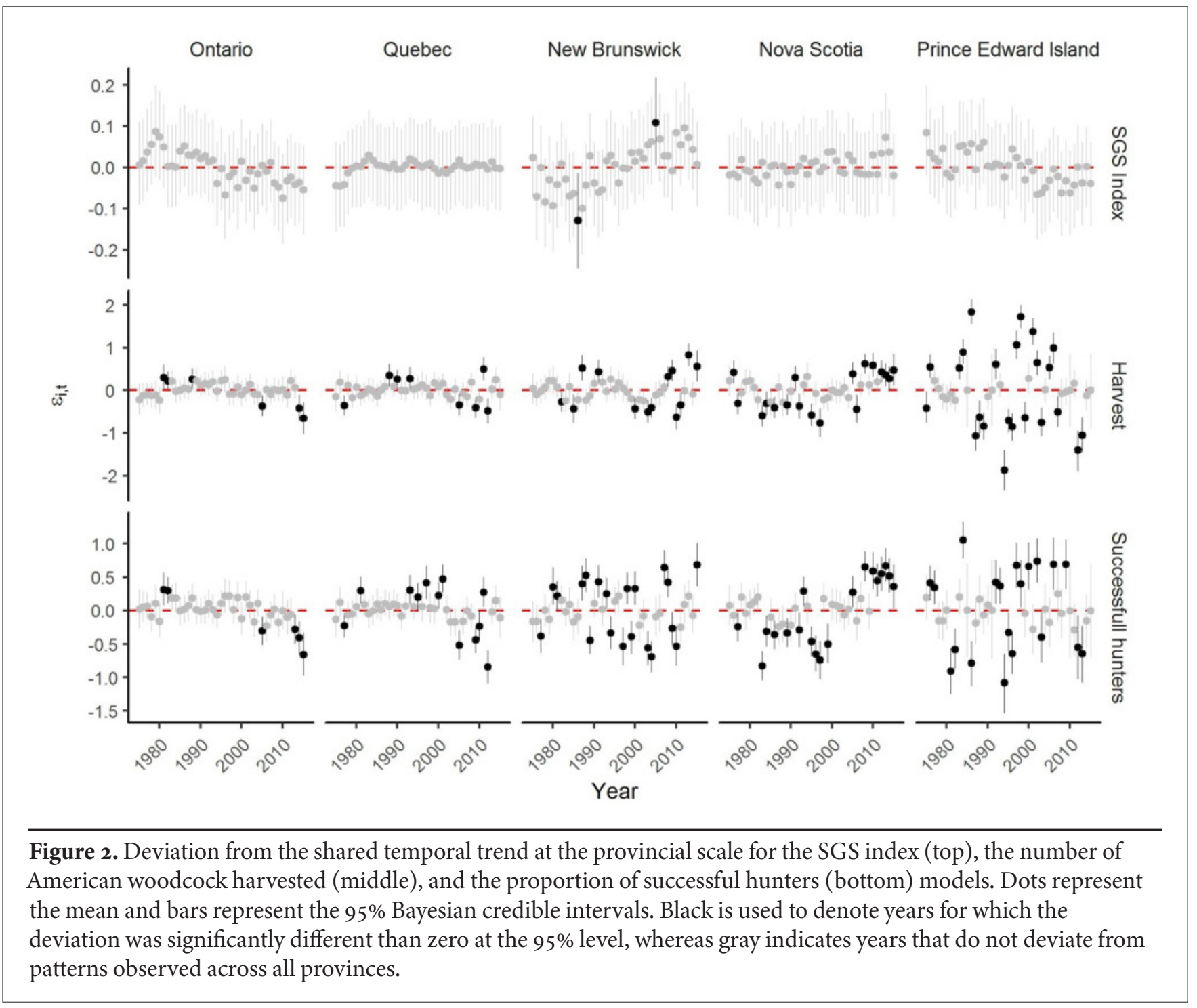

We used the number of hunters who successfully harvested a woodcock as the numerator and the number of active non-waterfowl hunters as the denominator. We used the same suite of variables as for the Total Harvest analysis and expected they would have similar effects.

Model fitting and inference We fitted all models using Stan version 2.14.1 called via the RStan package in $\mathrm{R}(\mathrm{R}$ Core Team 2016, Stan Development Team 2016). Stan implements Bayesian inference using a variant of the Hamiltonian Monte Carlo algorithm (Carpenter et al. 2016). We ran 3 chains, each of 500 iterations for the adaptation phase (discarded), followed by a further 1,000 iterations for inference. We checked for convergence by eye, and by using the Gelman-Rubin diagnostic test (Gelman et al. 2013). We deemed a parameter "significant" if the $95 \%$ Bayesian credible interval did not overlap zero and "weak" if the $90 \%$ credible interval did not overlap zero.

\section{Results}

\section{SGS POPULATION INDEX IN THE PROVINCES}

Predicted mean SGS survey index in Ontario was 6.80 males per route. The mean population index was significantly lower in Quebec (5.21; 95\% BCI $=5.04-5.38$ ), New Brunswick (6.29; 95\% BCI $=6.10-6.48)$, Nova Scotia $(3.14 ; 95 \% \mathrm{BCI}=3.04-3.12)$, and Prince Edward Island $(3.86 ; 95 \% \mathrm{BCI}=3.74-3.98)$. Spring snow $\operatorname{cover}(\hat{\beta}=0.00$; $95 \% \mathrm{BCI}=-0.01-0.01)$ and the amount of precipitation before the nesting season $(\hat{\beta}=-0.02 ; 95 \%$ BCI $=-0.06-$ o.03) did not significantly affect the SGS index over time. The lagged effect of snow cover $(\hat{\beta}=-0.01 ; 95 \% \mathrm{BCI}=-0.02$ -0.01 ), the amount of precipitation before the nesting season $(\hat{\beta}=-0.02 ; 95 \% \mathrm{BCI}=-0.07-0.03)$, the amount of precipitation during the nesting season $(\hat{\beta}=0.02 ; 95 \% \mathrm{BCI}=$ $-0.06-0.09)$, and the amount of precipitation during the fledgling season $(\hat{\beta}=0.02 ; 95 \% \mathrm{BCI}=-0.03-0.06)$ did not influence significantly the SGS population index. 
The population index declined by $70 \%(95 \% \mathrm{BCI}=$ $63-77 \%$ ) between 1975 and 2015 (Fig. 1b). The decline was slow and steady except for 2 periods of steeper decline; the first occurred during 1978-1984, and the second during 1992-1994. There was a significant period of upturn during 1982-1983 at the end of the first period of significant decline. There was also a significant period of downturn in 1990, just prior to the second period of significant decline. There was no significant deviation from the national pattern at the provincial level for the population index trend (Fig. 2).

\section{TOTAL HARVEST IN THE PROVINCES}

Mean annual harvest of woodcock in Ontario at the beginning of the study period was estimated at 3,379 individuals ( $95 \%$ BCI $=1,534-6,561$; Fig. 3a). Mean harvest was significantly higher in Quebec $(4,327 ; 95 \%$ BCI $=2,396-$ $7,214)$, and significantly lower in Prince Edward Island $(\hat{\beta}=453 ; 95 \%$ BCI $=289-679)$ compared to Ontario. Mean harvest in New Brunswick $(3,349 ; 95 \%$ BCI $=1,636$ $-6,267)$ and Nova Scotia $(2,714 ; 95 \%$ BCI $=1,915-3,745)$ was comparable to harvest in Ontario. The SGS population index had a positive effect $(\hat{\beta}=0.17 ; 95 \% \mathrm{BCI}=0.07$ -0.27 ) on the number of woodcock harvested. Based on model predictions, increasing the SGS population index by 1.0 would increase the harvest by $16 \%(B C I=4-28 \%)$. Spring snow cover had a negative effect on harvest $(\hat{\beta}=$ $-0.05 ; 95 \% \mathrm{BCI}=-0.10-0.00)$. Our model predicted that a delay of 2 weeks in snow cover, the largest delay observed in Ontario, would decrease hunter harvest by 10\% (BCI = $-19-0 \%)$. The amount of precipitation during the nesting season had a weak negative effect on woodcock harvest $(\hat{\beta}=-0.27 ; 95 \% \mathrm{BCI}=-0.57-0.04)$, whereas the amount of precipitation during the fledgling season had a weak positive effect on the number of woodcock harvested $(\hat{\beta}=$ $0.21 ; 95 \% \mathrm{BCI}=-0.01-0.44)$. As with snow cover, we used our model to predict the impacts of an abnormally wet breeding season and an abnormally wet fledgling season using the most extreme data point observed across years in Ontario. Our model predicted that if breeding season precipitation was $180 \mathrm{~mm}$ over the average, harvest would decrease by $9 \%(B C I=-20-1 \%)$, whereas an abnormally wet fledgling season, with precipitation $83 \mathrm{~mm}$ over the average, would increase the harvest by $7 \%(\mathrm{BCI}=\mathrm{O}-15 \%)$. The amount of precipitation before the nesting season did not influence the number of woodcock harvested $(\hat{\beta}=$ $-0.10 ; 95 \%$ BCI $=-0.31-0.12$ ).

There was a significant downturn in the Canadian harvest trend in 2004, and the harvest subsequently declined significantly during 2006-2010 (Fig. 3b), independently of the explanatory variable in the model. Subsequently, there was a significant upturn in the harvest during 2009-2014, and the trend in woodcock harvest reversed and increased significantly during 2013-2016. There were many signif-
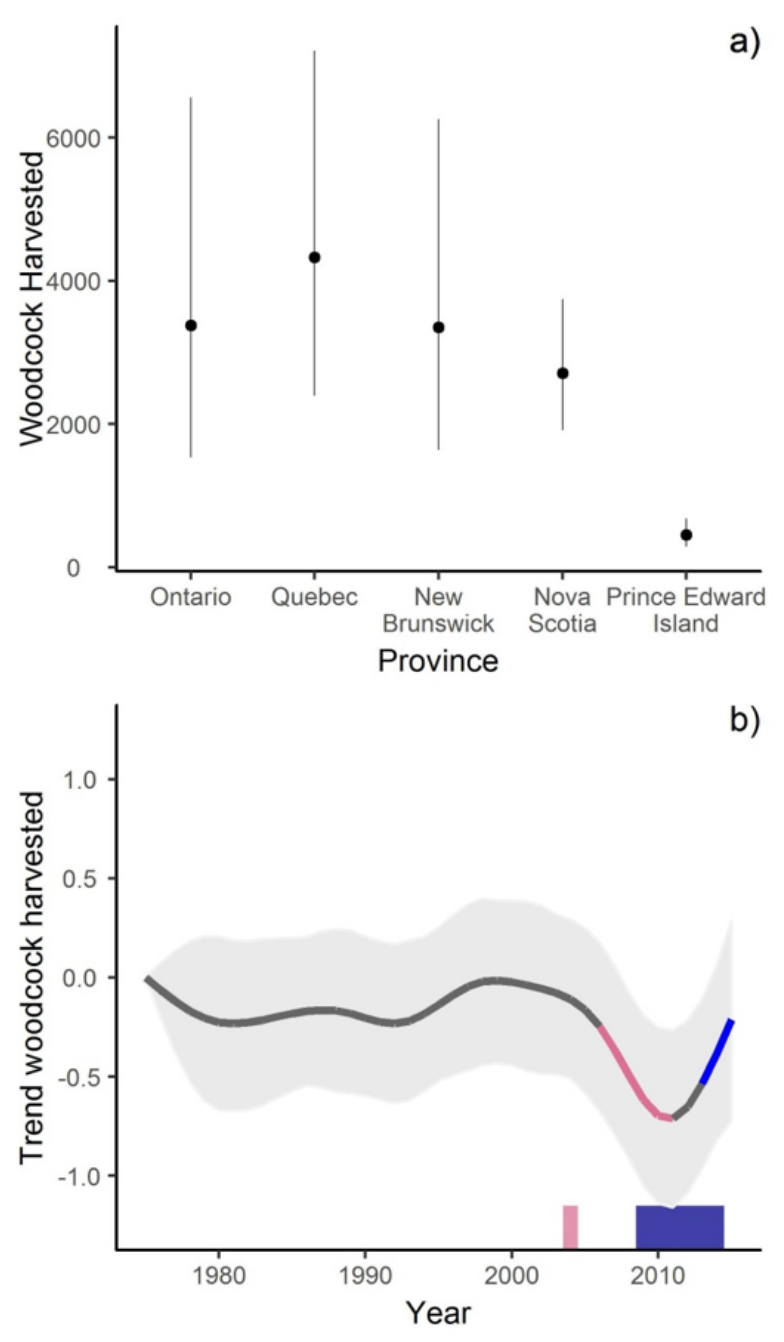

Figure 3. a) Estimated number of American woodcock harvested annually in each Canadian province at the beginning of the survey period. Dots represent the mean and bars represent the $95 \%$ Bayesian credible intervals. b) Shared temporal trend for woodcock harvest across all 5 provinces. The solid line is the estimated long-term component of the trend whereas the shaded area represents $95 \%$ Bayesian credible intervals. The trend line is colored for periods where there is a significant increase (blue) or decrease (pink) in the trend. Periods where the curvature is significantly positive (e.g., upturn; blue) or negative (e.g., downturn, pink) are identified by rectangle at the bottom of the figure. Predictions were made with a constant effort across region and time.

icant deviations from the national trend at the provincial level, but there was no consistent trend within a province (Fig. 2). Prince Edward Island was the province with the most significant deviations from the national trend, but this is more likely due to the small sample of hunters who 


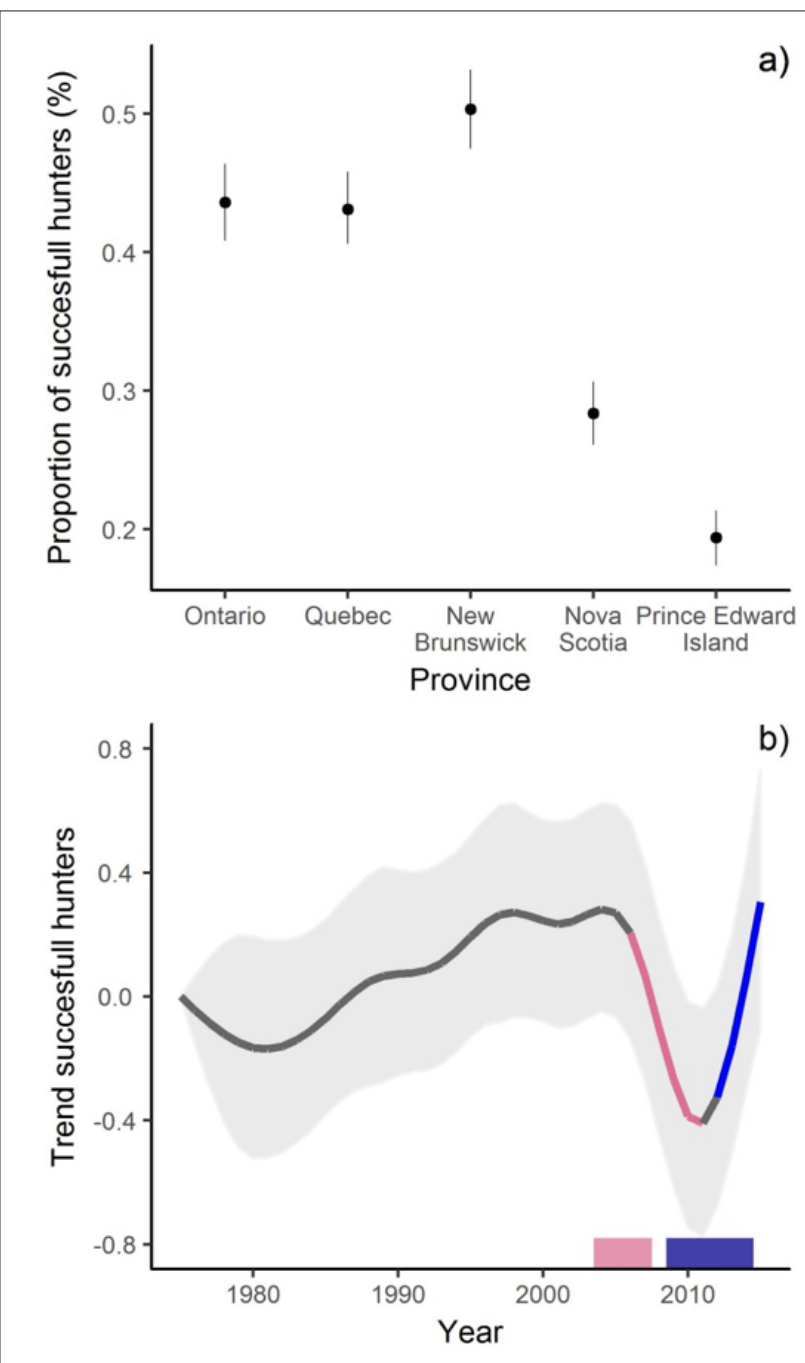

Figure 4. a) Estimated proportion of successful American woodcock hunters (number of hunters who harvested a woodcock over the total number of non-waterfowl hunters) in each Canadian province at the beginning of the survey period. Dots represent the mean and bars represent the $95 \%$ Bayesian credible intervals. b) Shared temporal trend in the proportion of successful woodcock hunters across all 5 provinces. The solid line is the estimated long-term component of the trend whereas the shaded area represents 95\% Bayesian credible intervals. The trend line is colored for periods where there is a significant increase (blue) or decrease (pink) in the trend. Periods where the curvature is significantly positive (e.g., upturn; blue) or negative (e.g., downturn, pink) are identified by rectangle at the bottom of the figure.

participated in the harvest survey in this province during these years. Woodcock harvest in Nova Scotia was consistently higher than the national average during the last 5 years of our study period.

\section{PROPORTION OF SUCCESSFUL} HUNTERS IN THE PROVINCES

On average, $44 \%(95 \%$ BCI $=41-46$; Fig. $4 a)$ of the non-waterfowl active hunters in Ontario harvested a woodcock. The proportion of successful hunters was significantly higher in New Brunswick (0.50; 95\% BCI $=0.47$ - 0.53 ), and significantly lower in Nova Scotia (0.28; $95 \%$ $\mathrm{BCI}=0.26-0.31)$ and Prince Edward Island (0.19; $95 \%$ $\mathrm{BCI}=0.17-0.21)$ compared to Ontario. Quebec hunter success $(0.43 ; 95 \% \mathrm{BCI}=0.41-0.46)$ was comparable to that in Ontario. The population index $(\hat{\beta}=0.16 ; 95 \% \mathrm{BCI}=$ $0.08-0.25$ ) had a positive effect on the proportion of hunters who were successful. According to model predictions, increasing the SGS population index by 1 would increase the proportion of successful hunters by $3 \%(\mathrm{BCI}=1-5 \%)$. Spring snow cover $(\hat{\beta}=-0.03 ; 95 \% \mathrm{BCI}=-0.07-0.01)$ presented a weak negative effect on the proportion of hunters who were successful. Our model predicted that a delay of 2 weeks in snow cover would decrease the proportion of successful hunters by $1 \%(B C I=-3-1 \%)$. Neither the total amount of precipitation before the nesting season $(\hat{\beta}$ $=-0.14 ; 95 \% \mathrm{BCI}=-0.33-0.04)$, during the nesting and brood rearing seasons $(\hat{\beta}=-0.03 ; 95 \% \mathrm{BCI}=-0.28-0.21)$, nor during the fledgling season $(\hat{\beta}=0.05 ; 95 \% \mathrm{BCI}=-0.12$ - 0.22 ) had a noticeable effect on the proportion of hunters who were successful.

The trend in the proportion of successful hunters showed an increase during 1990-2005, but there were no significant changes during this period (Fig. $4 \mathrm{~b}$ ). There was a sharp significant decline in the proportion of successful hunters during 2006-2011, but this decrease was counteracted by a sharp significant increase during 2012-2014. There was also a period of significant downturn in hunter success during 2004-2006, prior to the period of significant decline, and a period of significant upturn in the proportion of successful hunters during 2009-2014. At the provincial level, the success in Nova Scotia was consistently higher than the national average during the last 7 years of our study period, whereas it was consistently lower during the last 3 years in Ontario (Fig. 2). The other provinces did not show any consistent patterns.

\section{Discussion}

Climatic variables did not appear to influence the SGS population index in the Canadian provinces, but we did find support for climatic variables influencing woodcock harvest numbers. Both spring snow cover (i.e., the timing of snow melting in the spring) and breeding season precipitation negatively impacted woodcock harvest, whereas precipitation during the fledgling season increased the harvest. The discrepancy between the impacts seen in hunter harvest and in the SGS likely stems from the differential impact of climatic conditions on singing males and females/juveniles. Within 1 year (the temporal scale 
at which we analyzed these data) the spring conditions likely do not adversely affect the ability of breeding males to establish a singing territory, thus there is no detectable impact in the SGS. The same climatic conditions, however, may negatively impact female productivity and juvenile survival. A decrease in female productivity and juvenile survival would translate into a smaller fall population with fewer juveniles. Hunter success would diminish both in response to the overall smaller population and to the change in population age structure, given that juveniles are more vulnerable to hunting than adults (Reynolds 1987, Zimmerman et al. 2010). However, the effect of spring conditions on productivity and breeding season juvenile survival do not appear to carry over to the subsequent SGS population index in our model, which suggests that the climatic conditions on the breeding grounds are not a major limiting factor in the annual life cycle of woodcock in Canada.

\section{CLIMATIC CONDITIONS IN THE SPRING}

Hunting quality has often been linked directly to increased opportunities and hunter success (Decker et al. 1980). Schulz et al. (2010) proposed that the quality of the spring nesting season would be one of the most important factors affecting quality of the fall hunting season for woodcock. Our results partially support that contention. Late snow cover during the spring significantly decreased harvest and tended to decrease hunter success. Late spring snow cover can delay the start of egg laying, which can be detrimental to productivity by reducing time available to renest (Vander Haegen et al. 1993, McAuley et al. 1990). Persistent frost can also drive earthworms deeper into the ground, which limits the amount of energy available for nesting females (Rabe et al. 1983, Vander Haegen et al. 1993). In those instances, nesting females may reduce clutch size from 4 to 3 to compensate for the lack of available food (Sheldon 1971, Rabe et al. 1983, Vander Haegen 1992). The amount of precipitation during the nesting and brooding seasons, and the amount of precipitation during the fledgling season, also tended to affect harvest; the effect of precipitation, however, varied depending on season. Heavy rainfall during the nesting season was associated with a decrease in fall harvest, whereas a wet fledgling season was associated with an increase in harvest. The change in the direction of the effect is supported by previous studies. Abundant precipitation during the spring can limit the survival of pre-fledged woodcocks (Daly et al. 2015). In contrast, prolonged drought during summer can limit earthworm availability, which negatively affects woodcock survival (Rabe et al. 1983, Sepik et al. 1983). However, our analyses indicated that the effects of climatic variables on woodcock harvest and hunter success were weak at best, and any apparent within-year impacts on productivity by climatic variables did not produce a lasting effect reflected in the subsequent year's breeding population index. Favorable weather conditions during the breeding season are therefore likely to increase the subsequent fall's recruitment, and indirectly impact hunter success and woodcock harvest. However, the effect is unlikely to persist and govern population fluctuations to the same level seen, for example, in waterfowl nesting in the prairies (Feldman et al. 2016, Roy et al. 2016). The high mortality rate reported on the wintering grounds (Krementz et al. 1994, Pace 2000, Elizondo 2018) could act as buffering mechanisms against favorable weather conditions on the breeding grounds in the annual life cycle of woodcock. This question could be elucidated with a full annual life cycle model similar to those that have been developed for waterfowl populations (Robinson et al. 2016, Koons et al. 2017).

\section{LONG-TERM TRENDS}

SGS population index The most important decrease in the SGS population index occurred at the beginning of the survey in the late 1970s. There was a brief period of population stabilization in the late 1980 s, but since then the population has decreased slowly, except for a short period during 1992-1994 when there was a sharp significant decrease in the population index. Although decreases in early successional forest have been well-documented during this period in the eastern United States, this decrease in early successional habitat is less clear in eastern Canada (McAuley et al. 1996, Dessecker and McAuley 2001, Kelley et al. 2008). Undeniably, there has been some loss of early successional forest in each eastern Canadian province due to urbanization from the 1960 s to the 1970s. However, urbanization accelerated in the late 1980s (Dupras et al. 2016, Nazarnia et al. 2016), after the main period of woodcock population decline had abated. The agro-forested landscapes in eastern Canada also experienced modifications in the type of crop grown over this period, generally changing from hay and pasture to grain crops due to the decline in livestock production (Javorek et al. 2016). The amount of forest cover within agro-forested regions of eastern Canada, however, has remained either fairly stable or increased weakly because of the additions of hedgerows and windbreaks between fields and the increased amount of abandoned farmlands (Moss and Davis 1994, Jobin et al. 2014).

Major forest harvesting operations began during the 1950 s and 1960 s in eastern Canada and increased until the early 1980s, when the industry went through a major decline that slowed operations (Burton et al. 2003, Burton et al. 2006). As such, the 1960 os and 1970s correspond to a period when the amount of early successional forest increased on the landscape in eastern Canada (Etheridge et al. 2005, Boucher et al. 2006). The period of significant decrease in the number of woodcock detected in Canada is, therefore, not concomitant with a large-scale loss of 
habitat. A more thorough analysis at a smaller spatial scale could help elucidate this question. However, past studies at the local scale have questioned the representativeness of the SGS and even suggested that woodcock habitat might have been overrepresented in the early years of the survey, thereby biasing data from those years (Klute et al. 2000, Morrison et al. 2010). The decrease observed during the 1970 could therefore represent a return to a more normal representative population index (Morrison et al. 2010).

The continued long-term decline in woodcock abundance from the 1980 os onward is more concomitant with a large-scale decrease in the amount of woodcock habitat in southern Canada due to the combination of urbanization and changes in forestry and agricultural practices. It is important to note, however, that SGS coverage is currently limited in the northern range of the woodcock distribution, an area where timber harvesting has probably created the widest expanse of early successional forest (Keppie et al. 1984, Sauer et al. 2008). The northern region of Quebec also experienced a disproportionate amount of abandoned farm fields because of rural depopulation (Hamel et al. 1999 Roy et al. 2010, 2015). Woodcock could thus have shifted their distribution northward within their historical range, and the decline seen in the SGS could represent a trend that is only representative of the southern breeding population in Canada. A recent study by Sullins et al. (2016) lends credence to this hypothesis. Using stable isotopes analysis, they estimated that $>50 \%$ of the woodcock population could be missed by current SGS coverage. Nevertheless, woodcock harvest occurs in the southern Canada where the population declines have most likely occurred. Given the positive relationship we found between the SGS index and harvest, the low population index observed in southern Canada should be of concern for managers because it could affect hunter retention and recruitment (Roy et al., this volume, Factors influencing American woodcock hunter satisfaction in Canada). More targeted research programs in southern Canada could help identify areas of concerns that could be targeted for protection and enhancement.

Harvest and number of successful hunters Once effort and the spring population size were accounted for, our results suggest that harvest remained relatively stable over time. However, the proportion of successful hunters tended to increase, which supports in part the contention that only the most dedicated woodcock hunters are still practicing the sport (Guthrey et al. 2004, Willebrand et al. 2011). The decline in harvest and the proportion of successful hunters from ca. 2006 was unexpected, as there have been no regulatory amendments that could explain this pattern. Daily bag limits remained stable during the period of the analysis, and the mandated use of nontoxic shot for hunting migratory game birds in Canada in 1999 did not apply to woodcock. However, it is possi- ble that the drop in both metrics was due to issues related to productivity. The period of population decline corresponds roughly to a period of decline in annual indices of woodcock recruitment estimated by CWS from the Species Composition Survey (M. Gendron, unpublished data), and also to a period when the weighted annual indices of recruitment estimated by the USFWS were at their lowest in the Eastern Management Region (Seamans and Rau, this volume). It is therefore possible that woodcock productivity, and hence harvest, declined during this period due to factors that were omitted from our analysis.

\section{Management Implications}

Our finding showing that spring weather conditions are related to the subsequent fall harvest of woodcock in Canada brings some insight about the importance of extrinsic factors in affecting woodcock productivity. Given that our results suggest productivity could play a key role in hunter success, it would be worthwhile to investigate more directly the factors that drive female productivity and juvenile survival on the Canadian breeding grounds with more thorough field studies. Developing a full annual life cycle model would also be useful to identify the limiting factors and period for woodcock populations (Robinson et al. 2016).

The prolonged declines observed in the SGS population index in the Canadian provinces remain unexplained, and it would be useful to invest resources in analyzing the SGS index data at a finer scale. This analysis should help identify regions where declines were more pronounced and identify the drivers of this decline at a local scale. This undertaking should be facilitated by recent efforts that have been deployed to geo-reference SGS routes (Rau and Cooper, this volume).

\section{Acknowledgments}

The authors would like to thank all the volunteers and staff personnel that assist with the SGS, including personnel from the USFWS, CWS, state/provincial conservation agencies, and non-government conservation organizations. V. Aponte, E. Blomberg, E. Elizondo, G. McNeil and 2 anonymous reviewers provided constructive feedback on previous draft of this manuscript.

\section{Literature Cited}

Boucher, Y., D. Arseneault, and L. Sirois. 2006. Logging-induced change (1930-2002) of a preindustrial landscape at the northern range limit of northern hardwoods, eastern Canada. Canadian Journal of Forest Research 36:505-517.

Burton, P., C. Messier, G. Weetman, E. Prepas, W. Adamowicz, and R. Tittler. 2003. The current state of boreal forestry and the drive for change. Pages 1-40 in P.J. Burton, C. Messier, D.W. Smith, and W.L. Adamowicz, editors. Sustainable Management of the Boreal forest. NRC Research Press, Ottawa, Ontario, Canada.

Burton, P.J., C. Messier, W.L. Adamowicz, and T. Kuuluvainen. 2006 Sustainable management of Canada's boreal forests: progress and prospects. Ecoscience 13:234-248. 
Carpenter, B., A. Gelman, M. Hoffman, D. Lee, B. Goodrich, M. Betancourt, M.A. Brubaker, J. Guo, P. Li, and A. Riddell. 2016. Stan: a probabilistic programming language. Journal of Statistical Software 20:1-37.

Chen, M., P. Xie, J.E. Janowiak, and P.A. Arkin. 2002. Global land precipitation: a 50-yr monthly analysis based on gauge observations. Journal of Hydrometeorology 3:249-266.

Daly, K.O., D.E. Andersen, W.L. Brininger, and T.R. Cooper. 2015. Radio-transmitters have no impact on survival of pre-fledged American woodcocks. Journal of Field Ornithology 86:345-351.

Decker, D.J., T.L. Brown, and R.J. Gutiérrez. 1980. Further insights into the multiple-satisfactions approach for hunter management. Wildlife Society Bulletin 8:323-331.

Dessecker, D.R., and D.G. McAuley. 2001. Importance of early successional habitat to ruffed grouse and American woodcock. Wildlife Society Bulletin 29:456-465.

Duke, G.E. 1966. Reliability of censuses of singing male woodcock. Journal of Wildlife Management 30:697-707.

Dupras, J., J. Marull, L. Parcerisas, F. Coll, A. Gonzalez, M. Girard, and E. Tello. 2016. The impacts of urban sprawl on ecological connectivity in the Montreal Metropolitan Region. Environmental Science \& Policy 58:61-73.

Dwyer, T.J., E.L. Derleth, and D.G. McAuley. 1982. Woodcock brood ecology in Maine. Pages 63-70 in T.J. Dwyer, and G.L. Storm, editors. Woodcock ecology and management. Wildlife Research Report 14, U.S. Fish and Wildlife Service, Washington, D.C., USA.

Elizondo, E.C. 2018. Habitat selection, survival, and movement ecology of the American woodcock (Scolopax minor) in Louisiana USA. Thesis, Louisiana State University, Baton Rouge, Louisiana, USA.

Environment and Climate Change Canada [ECCC]. 2017. National Harvest Survey. <https://www.ec.gc.ca/reom-mbs/default. asp?lang=en\&n=CFB6F561> . Accessed 28 Feb 2018.

Etheridge, D.A., D.A. MacLean, R.G. Wagner, and J.S. Wilson. 2005. Changes in landscape composition and stand structure from 1945-2002 on an industrial forest in New Brunswick, Canada. Canadian Journal of Forest Research 35:1965-1977.

Evans, M.R. 2012. Modelling ecological systems in a changing world. Philosophical transactions of the Royal Society of London. Series B, Biological sciences 367:181-19o.

Feldman, R.E., M.G. Anderson, D.W. Howerter, and D.L. Murray. 2016. Temporal variability in the way local habitat affects duck population growth. Population Ecology:1-9.

Ferrand, Y., P. Aubry, F. Gossmann, C. Bastat, and M. Guénézan. 2010. Monitoring of the European woodcock populations, with special reference to France. Proceedings of the Tenth American Woodcock Symposium 10:37-44.

Fewster, R.M., S.T. Buckland, K.P. Burnham, D.L. Borchers, P.E. Jupp, J.L. Laake, and L. Thomas. 2009. Estimating the encounter rate variance in distance sampling. Biometrics 65:225-236.

Gelman, A., J.B. Carlin, H.S. Stern, D.B. Dunson, A. Vehtari, and D.B. Rubin. 2013. Bayesian data analysis. Third edition edition. CRC/ Chapman \& Hall, London, United Kingdom.

Gendron, M.H., and A.C. Smith. 2017. National Harvest Survey web site. http://ec.gc.ca/reom-mbs/enp-nhs/index. $\mathrm{cfm}$ ?do=def\&lang=e. 15 August 2017.

Guthery F.S., A.K. Crews, J.J. Lusk, R.N. Chapman, and M. Sams. 2004. Effects of bag limits on bobwhite hunters and harvest. Journal of Wildlife Management 68:1095-1103.

Hamel, S., G. Falardeau, and J.P.L. Savard. 1999. Les effets de la transformation des friches agricoles en plantations de pins sur les communautes d'oiseaux., Service canadien de la faune, région de Québec, Environnement Canada, Sainte-Foy, Québec, Canada. [In French].

Javorek S.K., Grant M.C. and S. Fillmore. 2016. Wildlife Habitat. Pages 64- 73 in Clearwater, R.L., T. Martin and T. Hoppe, editors. Environmental sustainability of Canadian agriculture: Agri-environmental indicator report series - Report \#4. Agriculture and Agri-Food Canada. Ottawa, Ontario, Canada.

Jobin, B., C. Latendresse, A. Baril, C. Maisonneuve, C. Boutin, and D. Côté. 2014. A half-century analysis of landscape dynamics in southern Québec, Canada. Environmental Monitoring and Assessment 186:2215-2229.

Kelley, J.R., S. Williamson, and T.R. Cooper. 2008. American woodcock conservation plan: a summary of and recommendations for woodcock conservation in North America. Compiled by the Woodcock Task Force, Migratory Shore and Upland Game Bird Working Group, Association of Fish and Wildlife Agencies. Wildlife Management Institute, Washington, D.C., USA.

Keppie, D.M., W.R. Watt, and G.W. Redmond. 1984. Male woodcock in coniferous forests: implications for route allocations in surveys. Wildlife Society Bulletin 12:174-178.

Klute, D.S., M.J. Lovallo, W.M. Tzilkowski, and G.L. Storm. 2000. Determining multiscale habitat and landscape associations for American woodcock in Pennsylvania. Proceedings of the Ninth American Woodcock Symposium 9:42-49.

Knape, J. 2016. Decomposing trends in Swedish bird populations using generalized additive mixed models. Journal of Applied Ecology 53:1852-1861.

Koons, D.N., T.W. Arnold, and M. Schaub. 2017. Understanding the demographic drivers of realized population growth rates. Ecological Applications 27:2102-2115.

Krementz, D. G, J.T. Seginak, D.R. Smith and G.W. Pendleton. 1994. Survival rates of American woodcock wintering along the Atlantic Coast. The Journal of Wildlife Management 58:147-155.

Longcore, J.R., D.G. McAuley, G.F. Sepik, and G.W. Pendleton. 1996. Survival of breeding male American woodcock in Maine. Canadian Journal of Zoology 74:2046-2054.

McAuley, D., D. Keppie, and R. Whiting Jr. 2013. American woodcock (Scolopax minor). in P.G. Rodewald, editor. The Birds of North America. Cornell Lab of Ornithology, Ithaca, New York, USA.

McAuley, D.G., J.R. Longcore, and G.F. Sepik. 1990. Renesting by American woodcocks (Scolopax minor) in Maine. Auk 107:407-410.

McAuley, D.G., J.R. Longcore, G.F. Sepik, and G.W. Pendleton. 1996. Habitat characteristics of American woodcock nest sites on a managed area in Maine. Journal of Wildlife Management 60:138-148.

Morrison, M., K. Connor, and G. Forbes. 2010. GIS-based assessment of American woodcock habitat at two spatial scales in New Brunswick. Proceedings of the Tenth American Woodcock Symposium 10:53-61.

Moss, M.R., and L.S. Davis. 1994. Measurement of spatial change in the forest component of the rural landscape of southern Ontario. Applied Geography 14:214-231.

National Oceanic and Atmospheric Administration [NOAA]. 2018. Precipitation reconstruction over land webpage. $<$ https://www. ncei.noaa.gov/data/snow-cover-extent/access/>. Accessed $28 \mathrm{Feb} 2018$

Nazarnia, N., C. Schwick, and J.A.G. Jaeger. 2016. Accelerated urban sprawl in Montreal, Quebec City, and Zurich: investigating the differences using time series 1951-2011. Ecological Indicators 60:1229-1251.

Pace, R.M. 2000. Winter survival rates of American woodcock in south central Louisiana. The Journal of Wildlife Management 64:933-939.

R Core Team. 2016. R: a language and environment for statistical computing. R Foundation for Statistical Computing, Vienna, Austria.

Rabe, D.L., H.H. Prince, and E.D. Goodman. 1983. The effect of weather on bioenergetics of breeding American woodcock. The Journal of Wildlife Management 47:762-771. 
Reynolds, R.E. 1987. Breeding duck population, production and habitat surveys, 1979-85. Transactions of the North American Wildlife and Natural Resources Conference 52:186--205.

Rau, R.D. and T.R. Cooper. 2019. American Woodcock Singing-ground Survey: the logistical challenges associated with route consistency through time. Pages 217-226 in D.G. Krementz, D.E. Andersen, and T. R. Cooper, Editors. Proceedings of the Eleventh American Woodcock Symposium. University of Minnesota Libraries Publishing, Minneapolis, Minnesota, USA.

Robinson, D.A., T.W. Estilow, and N.C. Program. 2012. NOAA climate date record (CDR) of northern hemisphere $(\mathrm{NH})$ snow cover extent (SCE), Version 1. NOAA National Centers for Environmental Information. DOI: 10.7289/V5No14G9.

Robinson, O.J., C.P. McGowan, P.K. Devers, R.W. Brook, M. Huang, M. Jones, D.G. McAuley, and G. Zimmerman. 2016. A full annual cycle modeling framework for American black ducks. Natural Resource Modeling 29:159-174.

Roy, C., L. Imbeau, and M.J. Mazerolle. 2010. Transformation of abandoned farm fields into coniferous plantations: is there enough vegetation structure left to maintain winter habitat of snowshoe hares? Canadian Journal of Zoology 88:579-588.

Roy, C., M.J. Mazerolle, and L. Imbeau. 2015. Transforming abandoned farm fields to conifer plantations reduces ruffed grouse density. Journal of Fish and Wildlife Management 6:405-417.

Roy, C., E.J.B. McIntire, and S.G. Cumming. 2016. Assessing the spatial variability of density dependence in waterfowl populations. Ecography 39:942-953.

Roy, C., Gendron, M., Meyer, S., Pollard, B. and Zimmerling, R. 2019. Factors influencing American woodcock hunter satisfaction in Canada. Pages 94-102 in D.G. Krementz, D.E. Andersen, and T. R. Cooper, Editors. Proceedings of the Eleventh American Woodcock Symposium. University of Minnesota Libraries Publishing, Minneapolis, Minnesota, USA.

Sauer, J.R., W.A. Link, W.L. Kendall, J.R. Kelley, and D.K. Niven. 2008. A hierarchical model for estimating change in American woodcock populations. Journal of Wildlife Management 72:204-214.

Schulz, J.H., D.R. Luukkonen, and R.O. Morgenweck. 2010. Improving woodcock management by implementing lessons from other migratory game birds. Proceedings of the Tenth American Woodcock Symposium 10:1-11.

Seamans, M.E., and R.D. Rau. 2016. American woodcock population status, 2016. U.S. Fish and Wildlife Service, Laurel, Maryland, USA.

Seamans, M.E., and R.D. Rau. 2019. American woodcock population status. Pages 9-16 in D.G. Krementz, D.E. Andersen, and T. R. Cooper, Editors. Proceedings of the Eleventh American Woodcock Symposium. University of Minnesota Libraries Publishing, Minneapolis, Minnesota, USA.

Sepik, G., R. Owen, and T. Dwyer. 1983. The effect of drought on a local woodcock population. Transactions of the Northeast Section of The Wildlife Society 40:1-8.

Sheldon, W.G. 1971. The book of the American woodcock. The University of Massachusetts Press, Amherst, Massachusetts, USA.

Stan Development Team. 2016. RStan: the R interface to Stan. Version 2.14.1. http://mc-stan.org/

Sullins, D.S., W.C. Conway, D.A. Haukos, K.A. Hobson, L.I. Wassenaar, C.E. Comer, and I.K. Hung. 2016. American woodcock migratory connectivity as indicated by hydrogen isotopes. The Journal of Wildlife Management 80:510-526.

Sutherland, W.J. 2001. Sustainable exploitation: a review of principles and methods. Wildlife Biology 7:131-140.

Vander Haegen, W.M. 1992. Bioenergetics of American woodcock during the breeding season on Moosehorn National Wildlife Refuge, Maine. Dissertation, University of Maine, Orono, Maine, USA.

Vander Haegen, W.M., W.B. Krohn, and R. Owen Jr. 1993. Effects of weather on earthworm abundance and foods of the American woodcock in spring. Proceedings of the Eighth American Woodcock Symposium 8:26-31.

Willebrand, T., M. Hörnell-Willebrand, and L. Asmyhr. 2011. Willow grouse bag size is more sensitive to variation in hunter effort than to variation in willow grouse density. Oikos 120:1667-167.

Zimmerman, G.S., W.A. Link, M.J. Conroy, J.R. Sauer, K.D. Richkus, and G.S. Boomer. 2010. Estimating migratory game-bird productivity by integrating age ratio and banding data. Wildlife Research 37:612. 


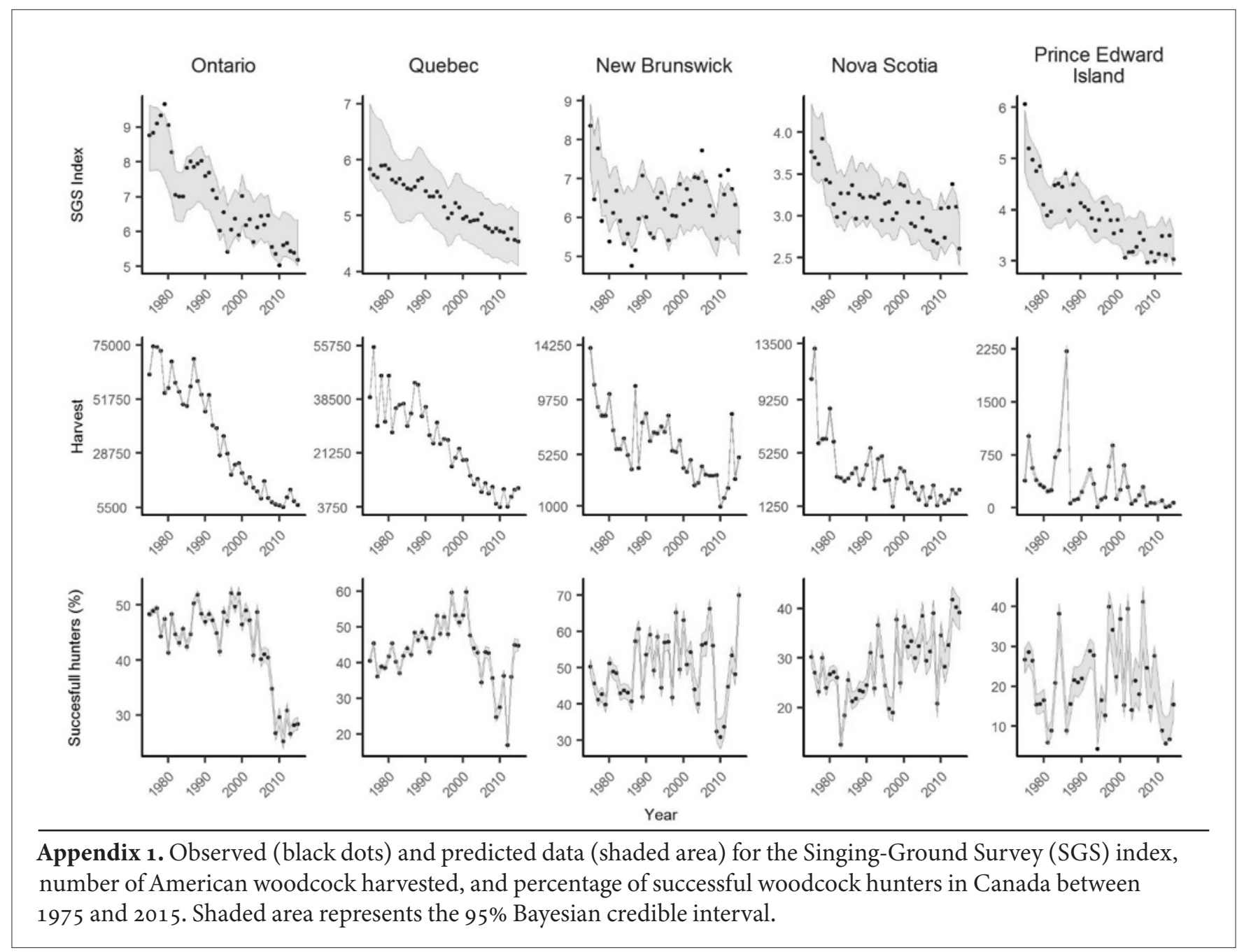

